\title{
Taxonomy and Identification of Finfish Eggs from Muthupettai, South East Coast of India
}

\author{
Selvam $\mathrm{J}^{1 *}$, Varadharajan $\mathrm{D}^{1}$, Babu $\mathrm{A}^{1}$ and Balasubramanian $\mathrm{T}^{\mathbf{1}}$ \\ ${ }^{1}$ Faculty of Marine Sciences, Centre of Advanced Study in Marine Biology, Annamalai University, Parangipettai-608 502, Tamil Nadu, India
}

\begin{abstract}
The fish seed resource is a major input for fish farming. There is a playing important role for increasing fisheries production, providing food and income as well as contributing to national economy. Fishes is a delicious and most important source of animal protein food. Since, the fish seed resource is an essential for food security, rural development and poverty alleviation. In the present investigation fin fish eggs belonging to 43 species of finfishes belong to 31 genera, 19 families, 8 orders, have been collected, identified and described in detail. Among the various finfish eggs collected, higher number of eggs were recorded for Cluepeids fishes, followed by Engraulids, Carangids, Cynoglossids, Tetraodontids, Teraponis, Mugilids, Atherinids, Synodontids, Ophichthids, Pristigastrids, Chirocentrids, Scombrids, Gerreids, Soleids, Bothids, Pleuronectids and Hemiramphids from Muthupettai waters.
\end{abstract}

Keywords: Finfish; Eggs; Culture; National; Economical development

\section{Introduction}

The knowledge on the early development of fin fishes in Indian waters is incomplete and more information is needed on the early life history of a large number of species. The prospective values of the studies on the planktonic fish eggs and larvae have been widely recognised in recent years especially after standardisation of techniques for their rearing [1-3]. Availability of extensive information on the biology of edible fishes is an essential prerequisite before planning for their proper management $[4,5]$ and for rational exploitation of these resources. For aquaculture practices, information on early developmental stages of commercially important finfishes is essential. However ichthyoplankton survey conducted over a period of two years along Muthupettai waters, few embryonic and early stages of fin fishes were collected and then visibly were identified.

\section{Materials and Methods}

The study was conducted at Muthupettai coast during between from January 2010 to December 2011. Finfish eggs were collected every month in the early hours of the day during high tide, with the help of plankton net of diameter $0.5 \mathrm{~m}$ made of bolting silk (No: 10 mesh size, $158 \mu \mathrm{m})$. Volume of water filtered was quantified with the help of a calibrated flow meter (General Oceanics, INC model) attached to it. The net was towed horizontally along the surface water at a constant speed of $1.0 \mathrm{~km} / \mathrm{hr}$ for about $15-20$ minutes in each station by adopting the method of $[6,7]$. Samples from all the stations were preserved onboard in $5 \%$ buffered formalin-seawater and sorted in the laboratory [8]. For identification of finfish eggs, the earlier investigations made by Delsman, Vijayaraghavan, Bensam, Job, Jones, and Venkataramanujam [9-25] were consulted. The photographs were taken by using a Sony Camera Measurement was taken micrometer fixed in the microscope.

\section{Guidelines used for the identification of pelagic eggs}

Presence or absence of oil globule

Pigmentation

Homogeneous or segmented yolk

Size of perivitelline space

Egg membrane with smooth or sculptured surface

\section{Size of the egg}

\section{Shape of the egg}

In late stage of development

Presence or absence of pigmentation on yolk sac or oil globule

Degree of pigmentation of eyes

Pigmentation patterns of embryo

Presence or absence of oil globule: Most of the fish eggs have single oil globule as in Sardines, Anchovies and Carangids whereas in other groups like Soleid and Cynoglossid - flat fishes, there may be several and some Engraulids and Clupeoids, have more than one oil globule, the number ranging from less than 10 to more than 50. A single oil globule may range in size from 0.03 to $>1 \mathrm{~mm}$ in diameter. Usually the oil globule is unpigmented to site an example Sardines, Synodontids, but in the eggs of certain Scombrides, Mugilids, Carangids, Leiognathids, Gerreids, Teraponids, it may be pigmented. Oil globules are absent in the eggs of some species or groups, to site an example; the families of Engraulidae (Stolephorus heterolobus, Thryssa sp.) and Pleuronectidae have no oil globules (Figures 1 and 2).

Pigmentation: While dealing with identification of eggs and larvae of Java Sea fishes relied mostly on pigmentation, which he has stated as the best diagnostic character. Usually, pigments present on the yolk, oil globule and embryo [9-12]. In eggs of some species such as Saurus sp., Mugilids, Carangids, Teraponids, Scombrids, Bothids,

*Corresponding author: Selvam J, Faculty of Marine Sciences, Centre of Advanced Study in Marine Biology, Annamalai University, Parangipettai-608 502, Tamil Nadu, India, Tel: 04144-243223; Fax: 04144-243553; E-mail: jagaselvam@yahoo.com

Received August 05, 2013; Accepted October 30, 2013; Published November 01,2013

Citation: Selvam J, Varadharajan D, Babu A, Balasubramanian T (2013) Taxonomy and Identification of Finfish Eggs from Muthupettai, South East Coast of India. J Cytol Histol 4: 193. doi: 10.4172/2157-7099.1000193

Copyright: (c) 2013 Selvam J, et al. This is an open-access article distributed under the terms of the Creative Commons Attribution License, which permits unrestricted use, distribution, and reproduction in any medium, provided the original author and source are credited. 
Citation: Selvam J, Varadharajan D, Babu A, Balasubramanian T (2013) Taxonomy and Identification of Finfish Eggs from Muthupettai, South East Coast of India. J Cytol Histol 4: 193. doi: 10.4172/2157-7099.1000193

Page 2 of 9

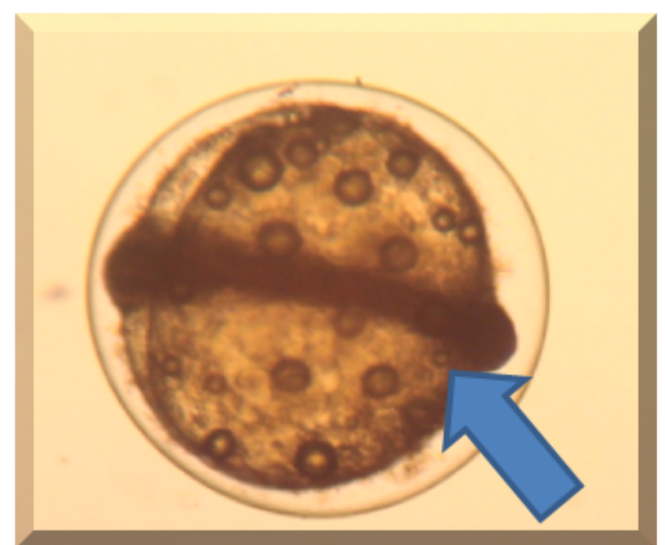

Figure 1: Oil globules: Photographs showing Egg with several oil globules.

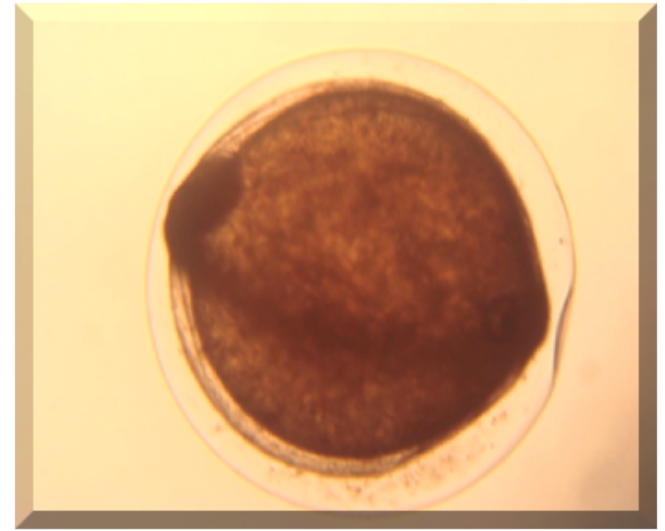

Figure 2: Oil globules: Photographs showing Egg with several oil globules.

Tetraodontids the embryos are pigmented. But in Scombrids, Mugilids, Gerreids, Tetraodontids, Leiognathids and Carangids the oil globules are pigmented. In Scombrids, Teraponids, Tetraodontids and Bothids yolks are pigmented.

The pigmentation of embryos, early fin development and myomeres count of the embryos are also employed for confirming the identification of fish eggs. The myomeres count usually varies between species to species. Eggs were measured using an ocular micrometer and the Photographs were taken for all the eggs with Kodak camera provided here.

Segmented or unsegmented yolk: The yolk is the most dominant part of fish eggs, usually segmented or vacuolated (fine, moderately fine, coarse) in lower teleost such as Engraulids, Clupeoids but it is homogenous in most of the higher teleost such as Synodontids, Mugilids and Cynoglossids. The yolk is usually unpigmented, to cite an example Engraulids, Clupeoids, but in some groups like Scombrids, Bothids, Teraponids and Tetraodontids, it is pigmented. Usually the yolk is colorless and transparent such as Clupeoids, Synodontids and Cynoglossids, but in some eggs, yolk is colored, for example in Pseudorhambus javanicus the yolk is light yellowish brown in color.

Perivitelline space: The eggs of higher bony fishes have a homogenous yolk and the perivitelline space is narrow (Mugiliformes, Perciformes, Pleuronectiformes and Tetraodontiformes). However, in lower bony fishes, yolk is vacuolated or segmented and a wide perivitelline space is present such as clupeoid fishes (Figures 3 and 4).

Membrane: The outer egg membrane (chorion) in most marine fishes is smooth and unornamented, but in few eggs, it is ornamented. For example, eggs belonging to the order Synodontiformes, the egg membrane has a honey comb-like polygonal network on the outer surface. The eggs of Myctophiformes have the spine like structure on the chorion. Hemiramphids and Exocoetids have the adhesive filaments (Figures 5 and 6).

Size of the egg: According to Ramaiyan et al. [26], most of the marine fish eggs (especially planktonic eggs) are in the size range of $0.5-4.0 \mathrm{~mm}$ in diameter. Bothid flat fishes have the small eggs, the size ranges between 0.5 to $0.8 \mathrm{~mm}$ whereas, Pleuronectid flat fishes have large eggs ranging from 4.0 to $4.5 \mathrm{~mm}$; eels have still larger eggs of about $5 \mathrm{~mm}$ in size. In eels, the large size may be due to hydration of the egg and the progressive development of Perivitelline space.

Majority of the planktonic marine finfish eggs are spherical in shape. For example, fishes belonging to the orders Clupeiformes, Mugiliformes, Aulopiformes, Atheriniformes, Perciformes, Pleuronectiformes and Tetraodontiformes have spherical eggs. Few eggs are ellipsoidal in shape; for example, fishes belonging to the family Engraulidae the eggs are ellipsoidal in shape. Eggs of Stolephorus indicus and S. commersoni are provided with a knob-like structure at one pole (Figures 7 and 8).

\section{Results and Discussion}

Taxonomical position of species: Classification of the fishes whose eggs are dealt with in the present work and their placement in Families

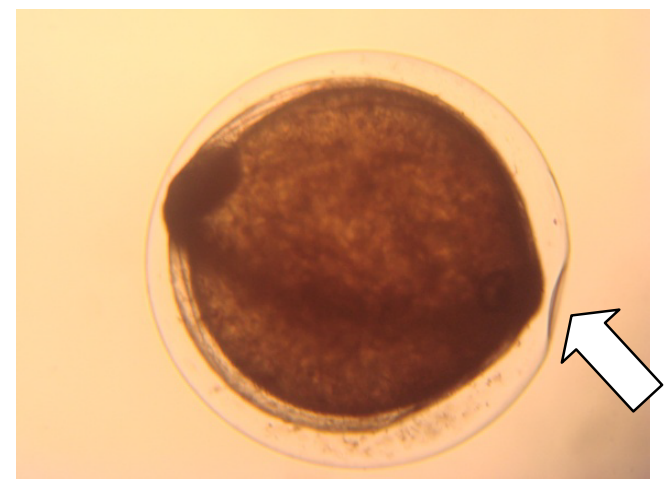

Figure 3: Size of perivitelline space- egg with wide perivitelline space

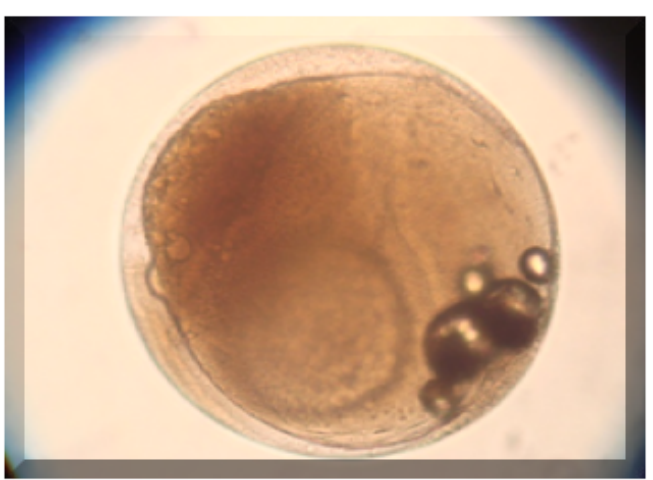

Figure 4: Size of perivitelline space: Egg with narrow Perivitelline space. 
Citation: Selvam J, Varadharajan D, Babu A, Balasubramanian T (2013) Taxonomy and Identification of Finfish Eggs from Muthupettai, South East Coast of India. J Cytol Histol 4: 193. doi: 10.4172/2157-7099.1000193

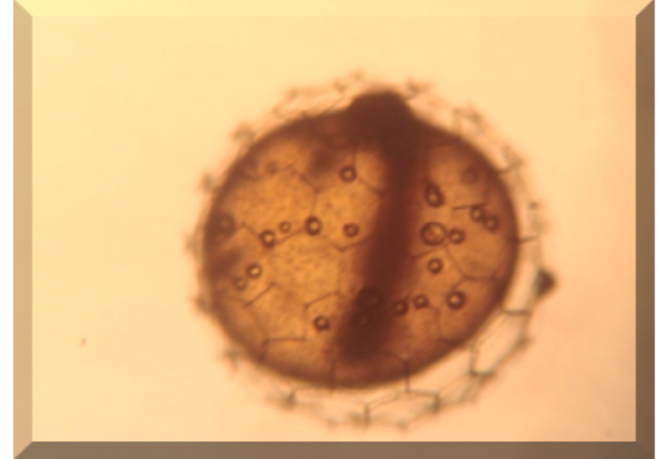

Figure 5: Egg membrane with smooth or sculptured surface: Sculptured egg membrane.

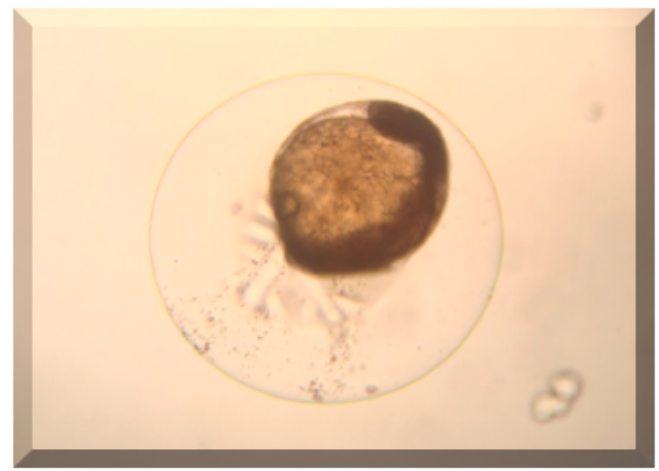

Figure 6: Egg membrane with smooth or sculptured surface: Smoothed egg.

as well as other taxa are largely as per the classification followed by Nelson [27-29]. Nomenclature of Subfamilies in Family Clupeidae is as per Whitehead [30] for other families as given by Nelson [28,29]. For the identification of fin fish eggs the methodology followed by previous workers such as Delsman, Vijayaraghavan, Job, Jones, Venkataramanujam, Whitehead and Nair $[9-17,19,23,25,30,31]$ was adopted.

$\begin{array}{ll}\text { Phylum } & \text { : Chordata } \\ \text { Sub Phylum } & \text { : Vertebrata } \\ \text { Super class } & : \text { Gnathostomata } \\ \text { Class } & \text { : Osteichthyes (Bony fishes) } \\ \text { Sub class } & \text { : Actinopterygii } \\ \text { Order } & \text { : Anguilliformes (Eels) } \\ \text { Family } & \text { : Ophichthidae (Snake eels) } \\ \text { Genus } & : \text { Ophichthys Ahl, 1787 } \\ \text { Order } & : \text { Clupeiformes (Herrings) } \\ \text { Family } & : \text { Engraulidae (Anchovies) } \\ \text { Genus } & \text { : Setipinna Swainson, 1839 } \\ \text { Species } & : \text { S. taty (Valenciennes, 1849) } \\ \text { Genus } & \text { : Stolephorus Lacepede, 1803 } \\ \text { Species } & : \text { S. tri (Bleeker, 1852) }\end{array}$

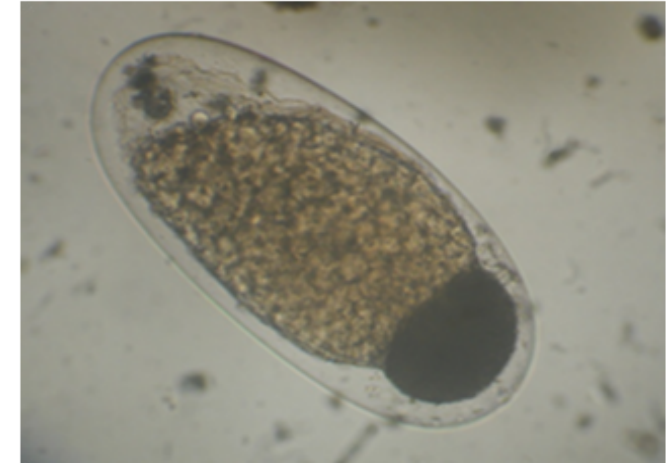

Figure 7: Shape of the egg: Showing the elliptical egg membrane.

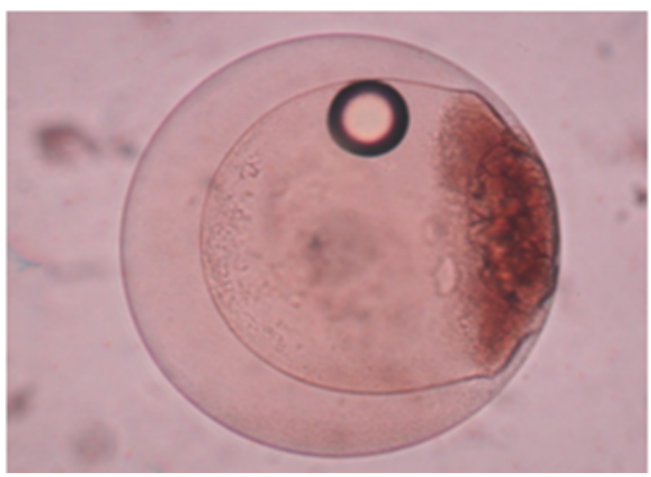

Figure 8: Shape of the egg: Showing the spherical egg membrane.

S. heterolobus (Ruppell, 1837)

S. punctifer (Fowler, 1838)

S. macrops (Hardenberg, 1933)

Genus : : Thryssa Cuvier, 1829

Species $\quad:$ T. dussumieri (Valenciennes, 1848)

: T. mystax (Bloch and Schneider, 1801)

: T. hamiltonii (Grey, 1833)

Family : Pristigasteridae

Genus

: Opisthopterus Gill, 1861.

Species $\quad:$ O. tardoore (Cuvier, 1829)

Family : Chirocentridae (Wolf herring)

Genus : Chirocentrus Cuvier, 1817

Species $\quad$ : C. dorab (Forsskal, 1775)

Family : Clupeidae (Herrings)

Genus : Escuolosa Whitley, 1940

Species $\quad$ : E. thoracata (Valencienne, 1847)

Genus : Sardinella Valenciennes, 1847

Species $\quad$ : S. fimbriata (Valenciennes, 1847)

: S. gibbosa (Bleeker, 1849) 
: S. longiceps (Valenciennes, 1847)

: S. clupeoides (Bleeker, 1849)

Genus : : Anadontostoma Bleeker, 1849

Species $\quad$ : A. chacunda (Ham. and Buch., 1822)

Genus : Nematolosa Regan, 1916

Species $\quad:$ N. nasus (Bloch, 1795)

Order : Aulopiformes

Family : : Synodontidae (Lizard fishes)

Genus : : Saurida Valenciennes, 1849

Species

: S. gracilis (Quoy and Gaimard, 1824)

: S. tumbil (Bloch, 1795)

Genus

: Saurus Cuvier, 1817

Order

: Mugiliformes (Mullets)

Family

Genus

: Mugilidae (Mullets)

Species

: Liza Jordon and Swain, 1884

: L. dussumieri (Valenciennes)

: L. tade (Forsskal, 1775)

Genus

Species

: Mugil Linnaeus, 1758

Order

Family

Genus

Family

Genus

Species

Order

: M. cephalus Linnaeus, 1758

: Atheriniformes (Toothcarps, Sandsmelts)

Family

Genus

Species

Genus

Genus

Species

Genus

Species

: Hemiramphidae (Half beaks)

: Hemiramphus Cuvier, 1817

: Atherinidae (Silversides)

: Pranesus

: P. pinguis (Lacepede, 1803)

: Perciformes (Perch-like fishes)

: Carangidae (Jacks and Pampanus)

: Carangoides Bleeker, 1851

: C. malabaricusBloch and Schneider, 1801)

: Caranx Lacepede, 1802

: Decapterus Bleeker, 1857

: D. russelli (Ruppell, 1830)

: Scomberoides Lacepede, 1802

Family

S. tol (Cuvier, 1832)

Genus

: Gerreidae (Mojarras)

Species

: Gerres Cuvier, 1824

Family

: G. oblongus (Cuvier, 1830)

Genus

$\begin{array}{ll}\text { Species } & : \text { T. jarbua (Forsskal, 1775) } \\ \text { Family } & : \text { Scombridae (Mackerels and Tunas) } \\ \text { Genus } & : \text { Scomberomorus Lacepede, 1802 } \\ \text { Order } & : \text { Pleuronectiformes (Flatfishes) } \\ \text { Family } & : \text { Pleuronectidae } \\ \text { Family } & : \text { Bothidae (Left-eye flounders) } \\ \text { Genus } & : \text { Pseudorhambus Bleeker, 1862 } \\ \text { Species } & : \text { P. javanicus (Day, 877) } \\ \text { Family } & : \text { Soleidae (Soles) } \\ \text { Genus } & : \text { Solea Klein, 1775 } \\ \text { Species } & : \text { S. ovata Richardson, 1846 } \\ \text { Family } & : \text { Cynoglossidae (Tongue fishes) } \\ \text { Genus } & : \text { Cynoglossus Hamilton and Buchanan, 1822 } \\ \text { Species } & : \text { Cynoglossus arel (Bloch and Schneider, 1801) } \\ & : \text { C. puncticeps (Richardson, 1846) } \\ \text { Order } & : \text { Tetraodontiformes (Puffers, Triggerfishes) } \\ \text { Family } & : \text { Tetraodontidae (Puffers) } \\ \text { Genus } & : \text { Arothron Mutter, 1839 } \\ \text { Species } & : \text { A. hispidus (Lacepede, 1758) }\end{array}$

\section{Descriptions of the species}

Ophichthys sp. (Snake eels): Eggs of Ophichthys sp. are pelagic, rounded, colorless and transparent. Diameter ranges from 2.30-2.80 $\mathrm{mm}$. Yolk is spherical, colorless, transparent and segmented. A single, yellowish oil globule, measuring the diameter of $0.5 \mathrm{~mm}$ and it is located opposite to the developing embryo in the yolk mass. Perivitelline Space is large. Nature of the Chorion is smooth and unpigmented. Identification of these eggs is based on the previous works of Delsman, Ramaiyan et al., Ganapati, Raju, and Manickasundaram [17,26,32-34].

Setipinna taty (Valenciennes, 1848), (Hair-fin anchovy): S. taty eggs are pelagic, rounded, colorless and transparent. The average diameter of the egg is $1.50 \mathrm{~mm}$. Yolk is spherical, segmented, transparent and colorless; the average diameter is $1.301 \mathrm{~mm} .12$ to 17 uneven sized oil globules were observed, the size ranges between $0.039-0.076 \mathrm{~mm}$. Oil globules are aggregated at the centre of the yolk mass. Perivitelline space is narrow. Nature of the Chorion is smooth, unpigmented. Identification of this egg is based on the works of Delsman, Ramaiyan et al., and Thangaraja $[16,26,32]$.

Stolephorus tri (Bleeker, 1852), (White bait): Eggs of S. tri are pelagic, colorless, transparent and elliptical in shape, measuring 1.38$1.57 \mathrm{~mm}$ in length and $0.56-0.71 \mathrm{~mm}$ in breadth. Yolk is elliptical and clearly segmented. Perivitelline Space is narrow. Single oil globule, pale yellow in color, measuring $0.07-0.15 \mathrm{~mm}$ in diameter situated at the posterior end of the yolk. Nature of the chorion is smooth. Egg is unpigmented in nature. Embryo indicated with few anterior myo Septemberta. Identification of this egg is based on the previous works done by Delsman, Job, john, Ramaiyan et al., Nair, Thangaraja and Manickasundaram [15,23,26,31,32,34].

Stolephorus punctifer (Fowler, 1838), (Buccaneer anchovy): The eggs of S. punctifer are pelagic, elliptical, colorless and transparent. 
Average length is $1.15 \mathrm{~mm}$ and breadth $0.52 \mathrm{~mm}$. Yolk is pear shaped, colorless, transparent and segmented. Oil globules are absent. Perivitelline space is Narrow. Nature of the Chorion is smooth. Egg is unpigmented. Identification of this egg is based on the works of Delsman, Ramaiyan et al., Nair and Bal and Pradhan [15,26,31,35].

Stolephorus heterolobus (Ruppell, 1837) (Short head anchovy): S. heterolobus eggs are pelagic, elliptical, colorless and transparent. The average length of the egg is $1.04 \mathrm{~mm}$ and average breadth is $0.55 \mathrm{~mm}$. Yolk is colorless, transparent, segmented. Oil globules are absent. Perivitelline space is narrow. Nature of the chorion is smooth. Pigmentation is absent. In developing embryos, eyes, head and trunk regions are well developed. Tail does not extend in the developing embryo. Identification of this egg is based on the works of Delsman, Ramaiyan et al., Venkataramanujam, Ramamoorthi and Sudarsan $[15,26,36,37]$.

Stolephorus macrops (Hardenberg, 1933) (White bait): S. macrops eggs are pelagic, elliptical, colorless and transparent. Length is $1.108-1.554 \mathrm{~mm}$ and breadth is $0.62-0.72 \mathrm{~mm}$. Yolk is elliptical, plainly vacuolated, colorless and transparent. Perivitelline space is very narrow. Single, yellow colored and transparent oil globule present at the posterior end of the yolk. Just above the oil globule, a small vacuole like structure is present. The size of the oil globule ranges between $0.06-0.128$ $\mathrm{mm}$. Nature of the chorion is smooth and without knob like structure. There is no pigmentation on any part of the egg. Identification is based on the works of Bapat, Delsman, Ramaiyan et al., Nair, Thangaraja, Venkataramanujam and Ramamoorthi $[1,15,26,31,32,36]$.

Thryssa dussumieri (Valenciennes, 1848) (Dussumier's anchovy): The eggs of $\mathrm{T}$. dussumieri are pelagic, rounded, colorless and transparent. Egg diameter ranges between $0.92-0.99 \mathrm{~mm}$. Yolk is spherical, vacuolated, colorless and transparent. Yolk diameter ranges between 0.89-0.99 mm. Oil globules are absent. Perivitelline space is Narrow. Nature of the chorion is smooth. Few myo Septemberta could be seen in the yolk. These eggs were identified based on the previous works of Job, John, Ramaiyan et al., Thangaraja, Venkataramanujam, Ramamoorthi and Chacko [23,26,32,36,38].

Thryssa mystax (Bloch and Schneider, 1801) (Mustached thryssa): T. mystax eggs are pelagic, rounded, colorless and transparent. Egg diameter ranges between $0.98-1.03 \mathrm{~mm}$. Yolk is spherical, segmented, colorless and transparent. The size of the yolk ranges between 0.92$0.99 \mathrm{~mm}$. Oil globules are absent. Perivitelline space is very narrow. Pigmentation is absent in the envelop. Identification is based on the previous works of Delsman, Ramaiyan et al., Whitehead, Thangaraja, Venkataramanujam and Ramamoorthi [13,15,26,30,32,36].

Thryssa hamiltonii (Grey, 1833): Eggs of T. hamiltonii are pelagic, rounded, colorless and transparent. The average egg diameter is $1.20 \mathrm{~mm}$. Spherical, colorless, transparent and segmented yolk is present. Oil globules are absent. Perivitelline space is narrow. Chorion is smooth with no pigmentation. Developed head, trunk, tail and myoSeptemberta are seen in the developing embryo and heart also developed. Identification is based on the previous works of Ramaiyan et al. Thangaraja, Venkataramanujam, Ramamoorthi and Abukhair Mohammad Mohsin and Mohd Azami Ambaki [26,32,36,39].

Opisthopterus tardoore (Cuvier, 1829) (Long-finned herring): O. tardoore eggs are pelagic, irregular rounded, colorless, transparent and devoid of oil globules. Egg diameter ranges between 0.69-0.99 mm. Yolk is spherical, vacuolated, colorless and transparent. Perivitelline width is quite narrow. Smooth envelop and the pigments are absent. For the identification, the works of Bensam, Venkataramanujam, Ramaiyan et al., Nair and Thangaraja $[21,24,26,31,32]$ were used.
Chirocentrus dorab (Forsskal, 1775), (Dorab wolf-herring): C. dorab eggs are pelagic, rounded, colorless and transparent. Egg diameter ranges between $1.68-1.72 \mathrm{~mm}$ (egg is easily recognized by their large size). Yolk mass is spherical, segmented, colorless and transparent, the yolk diameter ranges between 1.21-1.30 mm. 7-19 small sized oil globules are distributed irregularly in the yolk. Perivitelline width is narrow. The Egg membrane is not smooth but has on its surface a network of fine ridges which give it a honey comb appearance. Unpigmented in nature. These eggs are identified based on the works of Delsman, Ramaiyan et al. and Manickasundaram [9,26,34].

Escuolosa thoracata (Valenciennes, 1847) (White sardine): The species E. thoracata eggs are spherical, colorless and transparent. Egg diameter ranges from $0.80-0.86 \mathrm{~mm}$. Yolk is spherical, clearly segmented, colorless and transparent. Perivitelline width is large. 6-8 small, colorless and transparent and uneven sized oil globules (size ranging from $0.023-0.056 \mathrm{~mm}$ ) were present in the yolk. Egg membrane is smooth envelop. Melanophores present on the dorsal side of the developing embryo. These eggs are identified based on the works of Bapat, Ramaiyan et al., Manickasundaram, Bal, Pradhan, Venkataramanujam, Ramamoorthi and Chacko [1,24,26,34-36,38].

Sardinella fimbriata (Valenciennes, 1847) (Fringe scale sardine): S. fimbriata eggs are pelagic, rounded, colorless and transparent. Egg diameter ranges between $1.38-1.51 \mathrm{~mm}$. Yolk is spherical, vacuolated, colorless and transparent. perivitelline space is broad. Single, yellow colored oil globule is present on the yolk. Size of the oil globule ranges between 0.098-0.102 $\mathrm{mm}$. Chorion is smoothe with no pigmentation. Embryo is well developed with head and trunk. The eyes and auditory vesicle are clearly visible, based on the works by Bapat, Delsman, Job et al., Venkataramanujam and Ramaiyan et al. [1,11,23-26] the eggs were identified.

Sardinella gibbossa (Bleeker, 1849) (Gold stripe Sardinella): Eggs of S. gibbossa are pelagic, rounded, colorless and transparent. Egg diameter ranges from $0.52-0.81 \mathrm{~mm}$. Yolk is spherical, highly vacuolated and yellow in color, its diameter ranges between $0.45-0.55 \mathrm{~mm}$. Single and yellow colored oil globule is present on the. Size of oil globule ranges between $0.104-0.130 \mathrm{~mm}$. Perivitelline widths is narrow. Myotomes are visible through the transparency of the body. Few pigments present on the head and dorsal side of the developing embryo in late stage of eggs. Identification is based on the works accomplished by Bapat, Delsman, Bensam, Job, John, Ramaiyan et al., Venkataramanujam, Ramamoorthi and Chacko [1,11,20-26,36,38].

Sardinella longiceps (Valenciennes, 1847) (Indian oil sardine): S. longiceps eggs are pelagic, spherical, colorless and transparent. Egg membrane diameter varies between $1.52-1.61 \mathrm{~mm}$. Yolk is spherical, transparent, colorless and distinctly segmented and the diameter ranges between $0.89-1.33 \mathrm{~mm}$. There is a small less or more yellowish oil globule presented and the size ranges between $0.13-0.16 \mathrm{~mm}$. Perivitelline space is wide. Pigmentation is absent. The eggs of Sardinella longiceps identified based on the works of Delsman, Bensam, Ramaiyan et al. and Ganapati et al. [11,21,22,26,34].

Sardinella clupeoides (Bleeker, 1849) (Smooth belly Sardinella): S. clupeoides eggs are pelagic, spherical, colorless and transparent. Egg diameter ranges between $0.90-0.99 \mathrm{~mm}$. Yolk is spherical, vacuolated, colorless and transparent. The yolk diameter ranges between $0.51-0.55$ $\mathrm{mm}$. Oil globules are absent. Perivitelline width is large. Pigmentation is absent. In the late stage of embryonic development, it has well defined head, trunk and tail. Identification of this egg is based on the works of Job, John, Ramaiyan et al. and Venkataramanujam and Ramamoorthi [23,26,36]. 
Anadontostoma chacunda (Ham. and Buch, 1822) (Shortnosed gizzard): Eggs of A. chacunda are pelagic, perfectly rounded, colorless and transparent. Egg diameter ranges between 1.06-1.72 mm. Yolk is spherical, vacuolated, segmented, colorless and transparent; the diameter of the yolk mass ranging from $0.89-1.07 \mathrm{~mm}$. 2 to 5 uneven sized oil globules are present on the yolk, the size ranging between $0.0032-0.0087 \mathrm{~mm}$. Perivitelline space is narrow. Early eggs are unpigmented, however 23 distinct myotomes, pigmented and punctuate, black chromatophores uniformly distributed on the dorsal side of the developing embryo of the late stage of eggs. The works of Bapat, Delsman, Venkataramanujam, Bal, Pradhan and Chacko $[1,11,17,24,36,38]$ were employed for the identification.

Nematolosa nasus (Bloch, 1795) (Long-ray bony bream): Eggs of N. nasus are pelagic, spherical, colorless and transparent. Egg diameter ranges between 0.94-1 mm. Yolk is spherical, colorless, transparent and vacuolated, the vacuoles being fairly large in size. Golden yellow, uneven sized eight oil globules are present; the size ranging between 0.036$0.081 \mathrm{~mm}$. Usually the oil globules are found near the tail of the embryo. Perivitelline width is narrow. Pigmentation is absent in early eggs, but in late stages of the embryonic development, a few black pigment spots are noted on the dorsal side of the embryo. These eggs were identified based on the works of Job, John and Ramaiyan et al. [23,26].

Saurida gracilis (Quoy and Gaimard, 1824) (Slender lizard -fish): Eggs of S. gracilis are pelagic, perfectly spherical, colorless and transparent and an average egg measuring $1.02 \mathrm{~mm}$ in diameters. Yolk shape is spherical, clear, unsegmented filling practically the entire surface inside the egg membrane. Single colorless and transparent oil globule located at the centre of the yolk. Perivitelline width is narrow. Envelop is ornamented, fine network of hexagonal meshes are found on the surface of the egg membrane, the average mesh size being $0.03 \mathrm{~mm}$. The fine net-work of ridges on the egg membrane affords additional protection to the egg which is necessary for the longer time taken for the development of the embryo. In the mid stages of developing embryo, the embryo is fairly large in size and occupies the whole of the egg surface. The eyes and auditory vesicles are clearly seen. The heart has begun to beat very slowly and myotomes are faintly discernible. The trunk and tail regions of the developing embryo are also well developed. Pigmentation is absent. Identification is based on the works of Delsman, Venkataramanujam and Ramaiyan et al. [18,24-26].

Saurida tumbil (Bloch, 1795) (Common saury): S. tumbil eggs are pelagic, spherical, colorless, transparent and measuring $1.12 \mathrm{~mm}$ in diameter. Yolk is spherical, colorless, transparent, unsegmented and filling practically the entire space inside the egg membrane. Perivitelline width is narrow. Egg membrane is thin and ornamented, marked by network of hexagonal meshes of approximately equal size on the outer surface of the egg membrane. The hexagonal meshes project in the form of ridges, which are easily seen when viewed from the side, measuring $0.034 \mathrm{~mm}$ across. Pigments and Oil globules are absent. The embryo appears fairly large, with well developed head, trunk and tail regions. The eyes and the auditory vesicles are distinct. Identification of these eggs is based on the previous works of Venkataramanujam, Abukhair Mohammad Mohsin and Mohd Azami Ambaki [24,25,39].

Saurida sp. (Lizard fishes): Saurida eggs are pelagic, spherical, colorless and transparent, measuring $2 \mathrm{~mm}$ in diameter. Yolk is spherical, unsegmented, colorless and transparent; the diameter being $1.98 \mathrm{~mm}$. Perivitelline widths is narrow. Net-work of hexagonal meshes is found on the egg membrane. Pigments are absent. The identification is based on the earlier work of Delsman and Ramaiyan et al. [18,26].
Saurus sp. (Lizard fishes): Saurus sp. eggs are pelagic, spherical, pale whitish in color and measuring $1.12 \mathrm{~mm}$ in diameter. Yolk is spherical, granular, colorless and transparent; the diameter being 0.98 mm. 21 (22-28) oil globules are present, of these; 6-8 are large in size, the size ranging between $0.038-0.076 \mathrm{~mm}$, the average oil globule diameter being $0.05 \mathrm{~mm}$. These oil globules are irregularly distributed in the yolk. Perivitelline width is narrow. Bold hexagonal marking present on the egg membrane, distance between 2 opposite sides is $0.288 \mathrm{~mm}$, thickness of hexagons $0.0288 \mathrm{~mm}, 29$ ridges are present on the surface of the egg membrane, the distance between 2 ridges is $0.11-0.18 \mathrm{~mm}$. Few melanophores present on the dorsal side of developing embryo and few stellate chromatophores are present on the yolk. Identification is based on the works of Bapat, Delsman, Venkataramanujam and Ramaiyan et al. [1,18,24-26].

Synodontid Egg: Egg of Synodontid is pelagic, spherical, colorless and transparent; the average diameter being $2.05 \mathrm{~mm}$. Yolk is spherical, granular, colorless and transparent; the average diameter being 1.99 $\mathrm{mm}$. Single, colorless and transparent oil globule situated at the center of the yolk, the average measuring $0.44 \mathrm{~mm}$ in diameter. Perivitelline width is narrow. Bold hexagonal markings are present on the surface of the egg membrane, 17 ridges are present on the egg membrane, which affords additional protection to the egg which is necessary by the longer time taken for the development of the embryo. Unpigmented in nature. Identification of this egg is based on the work of Delsman and Ramaiyan et al. [18,26].

Liza dussumieri (Valenciennes): These eggs are pelagic, globular colorless and transparent; the diameter ranging between 0.53-0.57 $\mathrm{mm}$ and the average diameter being $0.55 \mathrm{~mm}$. Yolk is spherical, clear, colorless, transparent and unsegmented. Single oil globule is occupying the head portion of the developing embryo. The size range of the oil globule is between $0.154-0.1 .65 \mathrm{~mm}$ and the average diameter being $0.15 \mathrm{~mm}$. Perivitelline width is narrow. Pigments are present on the developing embryo; two patches of light yellowish brown pigments in the head region and black pigments intermingled with light yellowish brown chromatophores on the trunk and tail regions and similar pigment spots were noticed on the oil globule also. In early stage, the head, trunk and tail are not clearly visible. Identification of these eggs is based on the work of Job, John and Ramaiyan et al. [23,26].

Liza tade (Forsskal, 1775) (Tade mullet): L. tade eggs are pelagic, globular, colorless and transparent, measuring 0.65-0.76 $\mathrm{mm}$ in diameter. Yolk is spherical, clear, colorless and unsegmented. Single oil globule is presented on the yolk mass, measuring $0.10-0.18 \mathrm{~mm}$ in diameter. Perivitelline space is narrow. A few brownish black pigment spots present on the dorsal side of the body including head region of the embryo could be seen and such pigmentation is present on the oil globule also. Identification is based on the work of Job, John and Ramaiyan et al. $[23,26]$.

Mugil cephalus (Linnaeus, 1758) (Flathead mullet): M. cephalus eggs are pelagic, perfectly globular, colorless and transparent measuring 0.70-0.85 $\mathrm{mm}$ in diameter. Yolk is spherical, colorless, transparent, unsegmented with a diameter of $0.59-0.79 \mathrm{~mm}$. The egg is characterized by a prominent, large, single oil globule occupying the centre of the yolk mass. Size of the oil globule is $0.22 \mathrm{~mm}$ in diameter. Perivitelline space is narrow. Membrane of the Egg is very thin. Pigments scattered all over the embryo coloring black, brown and pale yellow. The chromatophores become more numerous and the grey pigments on the oil globule develop filamentous prolongations. The embryo is found to have developed prominent unpigmented eyes and auditory vesicles. The caudal end has elongated and is curved over the yolk and its tip almost reaches 
the oil globule. The embryo now extends over $3 / 4$ the circumference of the egg. The head and tail portions are quite distinct from the yolk mass. Identification of these eggs was based on the previous works of Venkataramanujam, Ramaiyan et al., Thangaraja, Manickasundaram, Venkataramanujam and Ramamoorthi $[24,26,32,34,36]$.

Hemiramphus sp. (Half beak): Hemiramphus sp. eggs are Pelagic, globular; slightly pinkish in color, measuring a diameter of $1.30 \mathrm{~mm}$. Yolk is spherical and unsegmented. Oil globules are absent. Perivitelline width is narrow. The surface of the egg membrane provides number of long and thin filaments. Pigmentation is absent. This description is in agreement with the description of Ramaiyan et al., Masuda et al. and Talwar $[26,40,41]$.

Pranesus pinguis (Lacepede, 1803) (Silver side): P. pinguis eggs are pelagic, spherical, without any sculpture, colorless and transparent and the average diameter of the egg being $0.59-0.62 \mathrm{~mm}$. Yolk is spherical and unsegmented measuring a diameter of $0.514-0.518$ $\mathrm{mm}$. Oil globules is absent. Perivitelline width is very narrow. Spot like black pigments are found scattered all over the egg and punctuate black pigments found scattered from the head to near the caudal region of the developing embryo. The embryo is very prominent with head (primordial brain, eyes and auditory vesicles) trunk (tubular heart) and tail, the developing eyes are very prominent but without pigmentation. These eggs were identified based on the works of Ramaiyan et al., Nelson, Thangaraja and Manickasundaram [26,28,32,34].

Carangoides malabaricus (Bloch and Schneider, 1801) (Malabar trevally): C. malabaricus eggs are pelagic, spherical, colorless and transparent; the average diameter measuring $0.94 \mathrm{~mm}$. Yolk is spherical, slightly segmented; measuring $0.93 \mathrm{~mm}$ in diameter. Single and prominent oil globule situated at the center of the yolk, measuring $0.21 \mathrm{~mm}$ in diameter. Perivitelline width is very narrow. Pale yellow punctate pigments present all over the body of the developing embryo, oil globule and the yolk. Developing eyes, auditory vesicles and somites are clearly visible. The somites are also very clear. Identification is based on the works of Ramaiyan et al. and Thangaraja [26,32].

Caranx sp. 1 (Trevally): Eggs of Caranx sp. 1 are pelagic, spherical, colorless and transparent, measuring $0.53-0.62 \mathrm{~mm}$ in diameter. Yolk is spherical, colorless and transparent; foam like segmented which is characteristic of Carangids, colorless and transparent egg membrane is smooth and the perivitelline width is narrow. Oil globule is single, colorless and transparent, measuring $0.116-0.149 \mathrm{~mm}$ in diameter and it is located at the centre of the yolk. Many black pigments are present on the oil globule, embryo and sometimes on the yolk mass also. The embryo is developed well. The head, eyes and the auditory vesicles with 2 statocysts are distinct. Black pigments are present on the inner surface of the oil globule and yellow pigments scattered all over the embryo Delsman, Venkataramanujam, Ramaiyan et al., Venkataramanujam and Ramamoorthi $[1,24-26,36]$ were consulted for the identification of these eggs.

Caranx sp. 2 (Trevally): Eggs of Caranx sp. 2 are pelagic, spherical, colorless and transparent. The average egg measuring a diameter of $0.72 \mathrm{~mm}$. Yolk is spherical, colorless and faintly segmented with large vacuoles (it's a characteristic of carangid eggs), colorless and transparent. Single, yellow colored oil globule is ventrally situated; the size ranging between $0.13-0.21 \mathrm{~mm}$. Perivitelline widths is narrow. The embryo is in advanced stage of development showing the well developed eyes, tubular heart and auditory vesicles; tail is free from the yolk. Ramifying chromatophores and black pigment cells are present on the oil globule and few melanophores present on the ventral side of the developing embryo. The eye and auditory vesicle of the embryo are distinctly visible Delsman, Venkataramanujam, Ramaiyan et al. and Thangaraja $[1,11,24$ 26,32] were employed for the identification of the eggs.

Decapterus russelli (Ruppell, 1830) (Indian shad): D. russelli eggs are pelagic, spherical, colorless and transparent, the size ranging between $0.7-0.76 \mathrm{~mm}$ in diameter. Yolk is spherical, slightly segmented, colorless and transparent, diameter being $0.58 \mathrm{~mm}$. Single and prominent, yellowish-brown colored oil globule is ventrally situated; the size being $0.14 \mathrm{~mm}$ in diameter, it has faint yellow tinge. Perivitelline width is narrow. Oil globule with numerous, thick brown punctate and filament like pigments, punctate brown pigments present all over the dorsal and ventral surface of the embryo from snout to caudal region of the developing embryo. Few stellate pigments are present on the head region of the developing embryo. On the trunk region of the developing embryo, black and yellow chromatophores are alternating each other. The developing embryo is well developed but the caudal region is free from the yolk mass and capable of moving occasionally. Previous works done by Delsman, Ramaiyan et al. and Manickasundaram [15,26,34] was used to identify the eggs.

Scomberoides tol (Cuvier, 1832) (Needle scaled queen fish): Eggs of S. tol are pelagic, spherical, colorless and transparent, measuring 0.66 $\mathrm{mm}$ in diameter. Yolk is spherical, prominently segmented, measuring a diameter of $0.62 \mathrm{~mm}$. Single and large oil globule located near the head of the embryo and size of the oil globule being $0.24 \mathrm{~mm}$ in diameter. Perivitelline width is narrow on lateral respects $(0.019 \mathrm{~mm})$, wide in cephalic and caudal regions $(0.045 \mathrm{~mm})$ of the developing embryo. Yellow with brownish yellow stellate pigments are present on the oil globule and brownish yellow pigments scattered all over the embryo. Developing eyes, heart and auditory vesicles are prominent. The preanal and post anal somites are clearly visible Ramaiyan et al. and Thangaraja $[26,32]$ described the eggs from Muthupettai waters.

Gerres oblongus (Cuvier, 1830) (Slender silver biddy): G. oblongus eggs are pelagic, spherical, colorless and transparent. The average size is being $0.63-0.73 \mathrm{~mm}$ in diameter (before preservation $0.4-0.5 \mathrm{~mm}$ in size). Yolk is spherical and vacuolated. Single oil globule is present measuring $0.21 \mathrm{~mm}$ in size. Perivitelline width is quite narrow. Oil globule is pigmented with black chromatophores. The vacuolated condition of the yolk and pigmentation of the oil globule are characteristic of the eggs of Job, Jones and Ramaiyan et al. $[23,26]$ described these eggs and his work was consulted.

Secutor ruconius (Hamilton, 1822) (Deep pug nose pony fish): Eggs of S. ruconius are pelagic, spherical, colorless and transparent measuring $0.66-0.68 \mathrm{~mm}$ in size (average: $0.67 \mathrm{~mm}$ ). Yolk is spherical, unsegmented located at the centre of the egg. The average diameter of the yolk being $0.652 \mathrm{~mm}$. Single and prominent oil globule, present at the center of yolk, measuring $0.17 \mathrm{~mm}$ in diameter. Perivitelline width is very narrow and unpigmented in nature. The work of Ramaiyan et al. and Thangaraja $[26,32]$ was used to identify the eggs.

Terapon jarbua (Forsskal, 1775) (Jarbua terapon): T. jarbua eggs are pelagic, spherical, colorless and transparent, the diameter of the egg being $0.56-0.62 \mathrm{~mm}$. Yolk is spherical, unsegmented (clear yolk showed a dark and glistering appearance). Oil globule is single, showing a dark and glistening appearance, the size is being $0.11 \mathrm{~mm}$. Size of oil globule is $0.12-0.15 \mathrm{~mm}$. Perivitelline width is very narrow. Oil globule and yolk contains large number of black, stellate and branching melanophores. In the developing embryo, clear, black punctate pigments are present on the head region and greenish pigments are present on the post cephalic and trunk regions. Works by Bensam, Job, Jones, Ramaiyan 
et al., Thangaraja, Manickasundaram and Chacko [21-23,26,32,34,38] were used for the identification of these eggs.

Scomberomorus sp. (Spanish mackerel): Eggs of Scomberomorus sp. are pelagic, perfectly spherical, colorless and transparent; with a diameter of $0.75-0.80 \mathrm{~mm}$. Yolk is spherical and unsegmented. Yellowish brown, single oil globule is present measuring $0.10-0.18$ $\mathrm{mm}$ in size. Perivitelline width is large. Brownish black pigments are sparsely distributed all over the yolk. Few chromatophores and spot like pigmentation are present on the oil globule. Pair of elongated strait line of chromatophores present just below the auditory vesicle, 3 small bands of chromatophores and several small pigments are scattered all over the developing embryo. Embryo is fairly advanced in development with the tail region being free from the yolk mass. The eyes and auditory vesicles are well developed. The embryo performs occasional jerking movements inside the egg membrane Delsman, Venkataramanujam, Ramaiyan et al., Manickasundaram, Venkataramanujam and Ramamoorthi [11,24$26,34,36]$ were used for the identification of the eggs.

Pleuronectid Egg: Pleuronectid eggs are pelagic, spherical, colorless and transparent, measuring a diameter of 4.05-4.85 mm. Yolk is spherical, unsegmented, colorless and transparent in nature. Oil globules are absent. Pigmentation is absent. In late stage of embryonic development, the developing embryo is fully developed with eyes, auditory vesicle and with distinct head, trunk and tail region. Caudal region of embryo is free from the yolk Ramaiyan et al. and Matarese et al. $[26,42]$ were used for the identification of these eggs.

Pseudorhambus javanicus (Day, 1877) (Javanese flounder): P. javanicus eggs are pelagic, spherical and light reddish brown in color. Egg diameter ranges between 1.04-1.07 mm. Light yellowish brown, spherical and unsegmented yolk. Perivitelline width is narrow. Numerous uneven oil globules are present; the size range being 0.05 $0.20 \mathrm{~mm}$. Grayish and branched chromatophores are scattered on the surface of the yolk, few black chromatophores on the developing embryo as well as on the surface of the yolk Venkataramanujam, Ramamoorthi, Ramaiyan et al. and Manickasundaram [25,26,34] described these types of eggs and their works were used to identify these eggs.

Solea ovata Richardson, 1846 (Ovate sole): Eggs of S. ovata are pelagic, spherical, colorless and transparent and the size ranging from 0.91-0.97 $\mathrm{mm}$. Yolk is spherical, large and unsegmented, lucid spherical space at the centre of the yolk, the size being $0.783 \mathrm{~mm}$. Numerous oil globules are arranged in cluster on the ventral and posterior part of the developing embryo. Perivitelline width is very narrow in the anterior side and wider in posterior side. Yolk and embryo are uniformly pigmented with brownish yellow punctate chromatophores. The works of Ramaiyan et al., Nair and Thangaraja $[26,31,32]$ were used for the identification of the eggs.

Cynoglossusarel (Bloch and Schneider, 1801) (Brown tonguefish): C. arel eggs are pelagic, spherical, colorless and transparent, measuring 0.64-0.66 $\mathrm{mm}$ in size. Yolk is spherical, unsegmented, colorless and transparent. 20-30 oil globules are concentrated at the anterior side of the egg, the oil globules are mostly smaller in size and some are relatively larger. The diameter of the oil globule ranges from 0.03-0.06 $\mathrm{mm}$. Perivitelline widths is very narrow and pigments are absent. The blastoderm has already spread over the surface of the yolk and appears as a cap surrounding the yolk. Works of Bapat, Venkataramanujam, Ramamoorthi, Ramaiyan et al., Thangaraja and Balakrishnan [1,24$26,32,43]$ were used for the identification of these eggs.

Cynoglossus puncticeps (Richardson, 1846) (Speckled tongue sole): C. puncticeps eggs are pelagic, perfectly spherical, colorless and transparent and the average size measuring $0.67 \mathrm{~mm}$ in diameter. Yolk is spherical, unsegmented, colorless and transparent measuring a size of $0.656 \mathrm{~mm}$. Number of oil globules are varied from $15-18$. These oil globules are uneven in size; the average size being $0.012 \mathrm{~mm}$. Mostly, these oil globules are spread all over the yolk and located at the centre of the yolk. Quite narrow perivitelline width. Embryo developes without any pigmentation on its body, 16 somites and rudiments of eyes are discernable. Venkataramanujam, Ramamoorthi, Ramaiyan et al. and Thangaraja [24-26,32] works were employed for the identification of these eggs.

Arothron hispidus (Linnaeus, 1758) (White-spotted puffer): Eggs of A. hispidus are pelagic, spherical, colorless and transparent, measuring $1.49 \mathrm{~mm}$ in diameter. Yolk is spherical, unsegmented, colorless and transparent. Single, pale yellow oil globule is present in the yolk, measuring $0.430 \mathrm{~mm}$ in size. Perivitelline width is narrow in lateral side $(0.122 \mathrm{~mm})$ and wide in anterior and posterior sides $(0.149 \mathrm{~mm})$. Prominent, black pigments present on the oil globule. In developing embryo, the body somites are not prominent but are marked by the pigments. Auditory vesicles and unpigmented eyes have also appeared. Works of Ramaiyan et al., Jones, Thangaraja, Sundaramanickam et al. and Prabhu $[26,27,32,44,45]$ were consulted for the identification of these eggs.

Arothron sp. (Blowfish): Eggs of Arothron sp. are pelagic, spherical, colorless and transparent; average egg diameter is $1.42 \mathrm{~mm}$. Yolk is spherical, unsegmented and the average yolk diameter is 1.11 $\mathrm{mm}$. A single, light yellowish oil globule is present, the size measuring from $0.27-0.30 \mathrm{~mm}$. Perivitelline width is narrow. Yolk is fully brownish pigmented. Four branched stellate chromatophores are present on the oil globule and brown pigments on the yolk. The sides of the embryo are deeply pigmented and few chromatophores are seen at the tail region of the developing embryo. The development of auditory vesicle and eyes could be seen clearly in the embryo. Works of Venkataramanujam, Ramaiyan et al., Jones, Thangaraja and Manickasundaram [24-27,32,34] were used for the identification of the eggs.

Mangrove has a generally been recognised as nursery and feeding grounds for most of the fishes. In the modern days, aquaculture is a fastest growing industry throughout the world to increase the fishes productions mainly in coastal aquaculture. Climatic or weather conditions are mainly affecting the species distribution from marine environment still, the favorable conditions occurs on the ecosystem because of the most organisms tolerate unfavorable conditions. Advance technology of finfish seed production as by induced breeding is sometimes fairly or absence, though the reason of genetic deterioration. Though, the collection of seeds are well from the natural environments are only the major source at present. Therefore, Muthupettai mangrove environment is one of the rich grounds for the finfish eggs resources. Some species in eggs are localized while others have a wide range of distribution. The density of fin fish eggs at all stations showed a seasonal variation. The maximum number of eggs were recorded during postmonsoon followed by premonsoon, summer and monsoon seasons. The seasonal occurrence of finfish eggs did not follow a similar pattern during the two-year period of study. This might be due to the fluctuation in the environmental parameters. The study was providing information on the sampling stations should be avoiding drainage wastes and some other pollution illegally releasing from the environment. There urgently be required prober management and further scientifical research for maintain the survive of species and safe demand of food. 
Citation: Selvam J, Varadharajan D, Babu A, Balasubramanian T (2013) Taxonomy and Identification of Finfish Eggs from Muthupettai, South East Coast of India. J Cytol Histol 4: 193. doi: 10.4172/2157-7099.1000193

\section{References}

1. Bapat SV (1955) A preliminary study of the pelagic fish eggs and larvae of the Gulf of Mannar and Palk bay. Indian J Fish 2: 231-255.

2. John MA (1951) Pelagic fish egg and larvae of the Madras coast. J Zool Soc India 3: 71-83

3. Devi LCB (1999) Seasonal and diurnal variation if both larvae in the seas around Andaman Nicobar area. Indian J Mar Sci 28: 187-209.

4. Ahlstrom EH, Moser HG (1976) Eggs and larvae of fishes and their role in systematic investigation and in fisheries. Rev Tran Inst Pearches Marit 40: 379-398.

5. Jones S, Pantulu VR (1958) On some larvae and juvenile fishes from the Bengal and Orissa coasts. Ibid 5: 118-143.

6. Venkataramanujam K, Ramamoorthi K (1972) Seasonal variation in fish eggs and larvae of Portonovo coastal waters. Proc Symp Warmwater Zooplank 474485.

7. Bensam P (1983) Observations on a few early developmental stages in some fishes of Porto Novo Coast, India. Ph.D. Thesis, Annamalai University.

8. Day F (1875-1888). Fishes of India, London.

9. Delsman HC (1924) Fish eggs and larvae from Java Sea. 3. A pelagic scomberoscoid egg. Treubia 5: 408-418.

10. Delsman HC (1925) Fish eggs and larvae of Java Sea. 4. Dussumieria hasseltii Blkr. Treubia 6: 297-307.

11. Delsman HC (1926) Fish eggs and larvae from Java Sea. 6. On a few carangid eggs and larvae. Treubia 8 ( 3 and 4): 212-218.

12. Delsman HC (1927) Fish eggs and larvae from Java Sea. 11. The genus Trichiorus. Treubia 9: 331-351.

13. Delsman HC (1929) Fish eggs and larvae from Java Sea. 12. The genus Engraulis. Treubia 11: 275-281.

14. Delsman HC (1930) Fish eggs and larvae from Java Sea. 14. The genus Pellona. Treubia 12: $37-45$.

15. Delsman HC (1931) Fish eggs and larvae from Java Sea. 17. The genus Stolophorus. Treubia 13: 217-243.

16. Delsman HC (1932) Fish eggs and larvae from Java Sea. 19. The genus Setipinna. Treubia 14: 109-114.

17. Delsman HC (1933) Fish eggs and larvae from Java Sea. 21. Eel eggs. Treubia 14: $237-247$

18. Delsman HC (1938) Fish eggs and larvae from Java Sea. 24. Myctophidea. Treubia 16: 415-420.

19. Vijayaraghavan $P$ (1957) Studies on the fish eggs and larvae of Madras coast Ph.D. thesis, University of Madras. India 79.

20. Bensam $P$ (1965) On the eggs and early larval stages of the Malabar sole Cynoglossus semifaciatus Day. Indian J Fish 112: 90-98.

21. Bensam P (1967) On a few post larval of Anadontostoma chacunda (Ham.) Indian J Fish 14 (1 and 2): 48-54.

22. Bensam $P$ (1972) A preliminary review of our knowledge of the early life histories of clupeiformes from Indian waters with provisional key for identifying the eggs and larvae. La Mer 9: 158-167.

23. Job TJ, Jones S (1938) Studies on the development of the Indian garfish Tylosurus strongylurus (van Hass.) with notes on the younger stages of Hemirhamphus gaimardi (C.V.) Rec Indian Mus 49: 245-253.

24. Venkataramanujam K (1975) Studies in fish eggs and larvae of Porto-Novo coastal waters. Ph. D. thesis, Annamalai University 283.
25. Venkataramanujam K (1975a) Life history and feeding habits of Ambassis commersoni (Cuvier) (Ambassidae, Teleosteii). In: NataraJanuary R (ed.) Recent Researches in Estuarine Biology, Hindustan Publ Corp., New Delhi, India.

26. Ramaiyan V, Balasubramanian T, Kannupandi T, Ajmal Khan S, Rajagopal S, et al. (2005) Monograph on Eggs abd Larvae of Fin and Shell Fish Collected from Parangipettai and Adjacent Waters Along the South East Coast of India. Annamalai University, India, Monograph 148.

27. Jones S, Sujansinghani KH (1954) Fish and Fisheries of the Chilka Lake with statistics of the fish catches for the years 1948-50. Indian J Fish 1 (1 and 2) 256-344.

28. Nelson JS (1976) Fishes of the world. Word, Wiley-Interscience, New York USA.

29. Nelson JS (2006) Fishes of the World (4thedn.) John Wiley and Sons Inc., New York, USA.

30. Whitehead PJP (1963) A review of the elopoid and clupeoid fishes of the Red sea region. Bull Br Mus Nat Hist Zool 12225

31. Nair RV (1952) Studies on some post-larval fishes of the Madras plankton. Proc Indian Acad Sci 35: 203.

32. Thangaraja M (1982) Studies on development, distribution and abundance of fish eggs and larvae in the Vellar estuary, Porto-Novo (South India). Ph. D. thesis, Annamalai University 165

33. Ganapati PN, Raju NS (1961) On the eggs and early development of eels of Waltair coast. J Zool Soc India 12: 229-238

34. Manickasundaram M (1990) Studies on fish eggs and larvae of Coleroon estuary along the southeast coast of India. Ph.D. thesis, Annamalai University 190.

35. Bal DV, Pradhan LB (1946) Second progress report on "Investigation of fish eggs and larvae from Bombay waters", 1945-46. Govt. Central Press, Bombay 16.

36. Venkataramanujam K, Ramamoorthi K (1981) Fish eggs of Porto novo coasta waters, east coast of India. Rapp Pv Reun Cons Int Explore Mer 178: 597-599.

37. Sudarsan D (1967) Eggs and larvae of a Hemirhamphid fish from Mandapam J Mar Biol Ass India 8: 342-346.

38. Chacko PI (1950) Marine plankton from the water around Krusadi Island. Proc Indian Acad Sci 31: 162-174.

39. Abukhair Mohammad Mohsin, Mohd Azami Ambaki (1996) Marine fishes and fisheries of Malaysia and neighboring countries. University Pertanian Malaysia Press, Serdang, Malaysia 743.

40. Masuda H, Amoka K, Araga C, Uyeno T, Yasino T (1984) The fishes of the Japanese Arichi pelag. Tokai University Press, Japan 437.

41. Talwar PK (1967) Studies on the biology of Hemirhamphus marginatus (Forskal) (Hemirhamphidae - Pisces). J Mar Biol Ass India 9: 61-69.

42. Matarese AC, Kendall Jr AW, Blood NM, Vinter BM (1989) Laboratory guide to early life history stages of northeast Pacific fishes. NOAA Tech Rep NMFS 80: 652

43. Balakrishnan KP (1961) Fish eggs and larvae collected by the Researdi Vesse Conch during 1958-1961. 1. Larvae of Cynoglossus sendfasciatus Day. Bull Cent Res Inst Unt Kerala C8: 131-139.

44. Sundaramanickam A, Vijayalakshmi S, Balasubramanian T (2007) Assessment of Tsunami Impact on Fish Eggs and Larvae along Parangipettai Coast (south east coast of India). J Fish Aqua Sci 2: 120-130.

45. Prabhu MS (1956) Maturation of intraovarian eggs and spawning periodicities in some fishes. Indian J Fish 3: 59-90. 